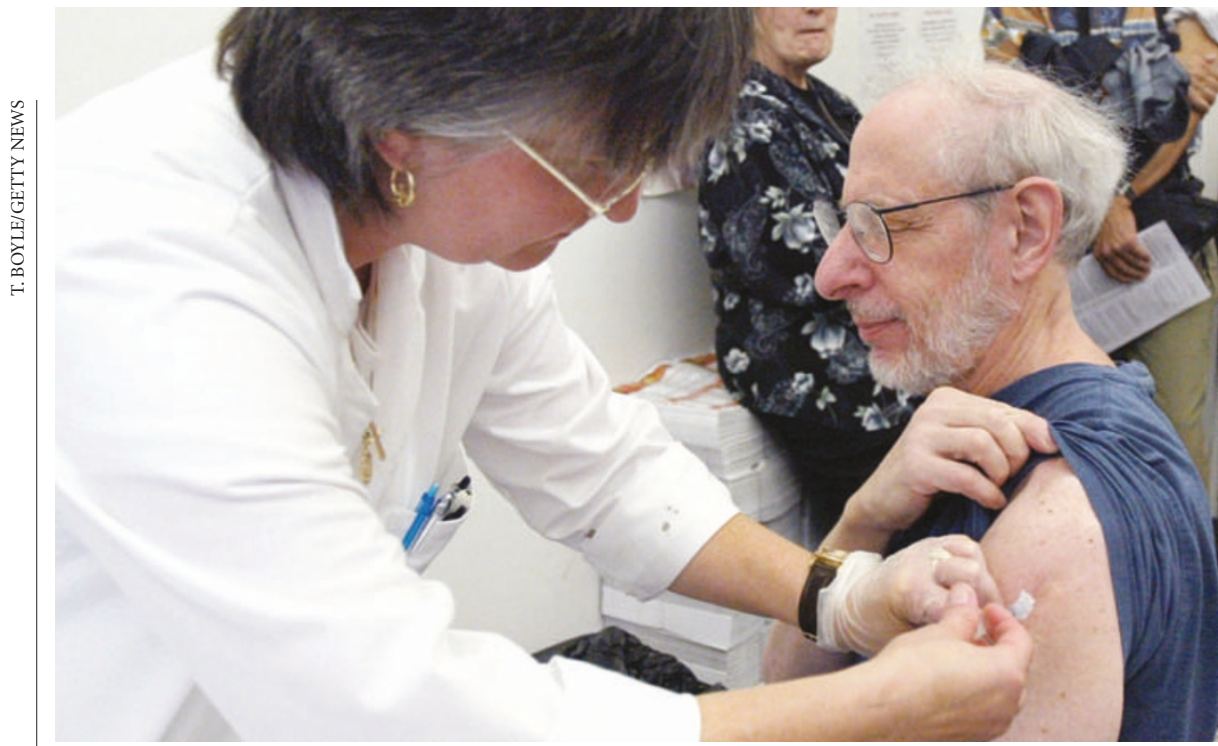

Ill-prepared: although flu vaccines are made every year, the world is not equipped to fight a pandemic.

\title{
WHO calls for vaccine boost to prepare for flu pandemic
}

\section{Erika Check, Washington}

Alarmed by bird flu's grip on southeast Asia, the World Health Organization (WHO) is calling for action. Last week, WHO officials met with vaccine makers, public-health experts and government representatives in a bid to speed up the production of flu vaccines to avert a global pandemic.

The three flu pandemics of last century — in 1918, 1957 and 1968 — were sparked when avian flu jumped the species barrier and became infectious in humans. The WHO has been warning for two years that conditions are right for a new pandemic yet vaccines are still not available.

Theoretically, little stands in the way of preparing pandemic flu vaccines - the annual manufacture of vaccines for normal flu is routine. But companies and governments have been reluctant to invest in a vaccine that would never be used if the threat of a pandemic abates.

"The vaccines need to be tested, and that costs money," said Klaus Stöhr, coordinator of the WHO's global influenza programme, at the 12 November meeting. "That is the single most important barrier to pandemic vaccine development."

The strain of bird flu now circulating in Asia - known as H5N1 — has already killed 44 people this year, but does not seem able to spread from person to person, yet. WHO officials said at the meeting that the $\mathrm{H} 5 \mathrm{~N} 1$ strain seems to be increasing in virulence in chickens and mice, and may have found a reservoir in domestic ducks. The ducks can be infected for a lengthy period while appearing healthy, and could spread the disease back into poultry, and possibly humans, said WHO officials. The incubation of the virus in these different species may favour its evolution into a strain that can spread among humans.

But just two companies are currently testing a pandemic flu vaccine, and only a handful of countries have funded clinical trials of the vaccines. The WHO urged an acceleration of these efforts. "We can get our homework done now to ensure that when it matters most to get vaccines produced, it can happen immediately," Stöhr said. "We don't want to miss this chance."

Stöhr also noted the need to resolve inconsistencies in policies among international regulatory agencies, to avoid duplicating costly clinical trials (see Nature 432, 137;2004).

But the initiative still has challenges to face, said Stöhr. A major barrier is that patents on a crucial technology, called reverse genetics, are held by one company, MedImmune in Gaithersburg, Maryland. The technology has the potential to accelerate the process by which vaccines are selected and produced. Other companies hold associated patents. Representatives from industry told the meeting that dealing with patent issues has proved to be a major impediment for vaccine development in the past.

Some governments have begun to take action. The US National Institutes of Health is funding pandemic flu vaccine trials. The US health department also said on 9 November that it has issued a \$10-million contract to secure a year-round supply of eggs needed to grow the volume of virus necessary for a pandemic flu vaccine. And Japan has expressed interest in funding trials, say WHO officials.

These efforts are admirable, but they are not enough, said Arlene King of Canada's Public Health Agency, who attended the Geneva meeting. "Pandemic influenza will be the biggest public-health emergency we ever face," she said.
Grant-transfer plan paves the way for European mobility

Barbara Simm, Munich

European researchers look set to enjoy a mobile future. The scientific borders of ten nations have been loosened to allow national grants to be spent in other countries.

The requirement for grants to be spent on research in the home nation was seen by many as a hindrance to mobility in Europe. And that in turn was cited as a major competitive disadvantage compared with the United States.

Now the heads of Europe's national research councils (collectively known as EUROHORCS) have hammered out an agreement to let researchers take their grants to an institute in a participating country without needing approval. The transfer can be made as long as the funded project is already under way, and its funding has at least six months left to run.

The agreement was signed on 22 October by the heads of 12 research councils from ten European nations, but it was made public only last week. Among those who signed were Britain's Engineering and Physical Sciences Research Council (EPSRC) and its Particle Physics and Astronomy Research Council. The main national research agencies in France, Switzerland and Finland intend to join by the end of the year, and the remaining UK research councils are likely to follow suit, says Christoph Mühlberg, head of international affairs at Germany's research funding body the DFG, which currently chairs EUROHORCS.

The DFG already has a number of bilateral agreements for cross-border grant validity, for example with the EPSRC and the Austrian Science Fund (FWF). But Mühlberg says that the EUROHORCS agreement is a major step towards border-free research mobility throughout Europe.

Many researchers are enthusiastic about the agreement. "Being able to move without a lot of red tape, grant-wise, makes it infinitely easier to establish a scientific career abroad," says Marcus Koch, an Austrian plant scientist who moved to the University of Heidelberg in Germany last year, shortly after the bilateral agreement was signed between the DFG and the FWF. "Bringing my Austrian grant money to Germany spared me so much time and trouble."

Other countries participating in the EUROHORCS programme include Spain Austria, Belgium and the Netherlands. 